\title{
Cement leakage following percutaneous kyphoplasty in a patient after a posterior lumbar fusion: a case report
}

\author{
Ziquan $\mathrm{Li}^{1}$, Keyi Yu ${ }^{1 *}$, Xiao Chang ${ }^{1}$, Siyi $\mathrm{Cai}^{1}$, Jun $\mathrm{GaO}^{2}$ and Yipeng Wang ${ }^{1}$
}

\begin{abstract}
Background: Percutaneous kyphoplasty (PKP) has become an important minimally invasive surgical technique for fracture stabilization and pain relief in patients with vertebral compression fractures. However, intraspinal cement leakage following PKP is a serious postoperative complication that can lead to morbidity and mortality.

Case presentation: We describe an uncommon case of epidural leakage of bone cement in an 81-year-old woman who underwent posterior lumbar decompression and fusion from L3-5 4 years prior and had an unremarkable postoperative course. The patient was admitted to Peking Union Medical College Hospital with complaints of muscle weakness and severe low back pain radiating to the left thigh 1 week after PKP of L5 due to an acute osteoporotic compression fracture. Computed tomographic imaging revealed massive leakage of cement into the spinal canal at L5-S1, and therefore, surgical decompression and removal of epidural cement were performed carefully without causing a dural tear. She improved remarkably and no neurologic deterioration was observed in the postoperative period during the one-year follow-up.
\end{abstract}

Conclusions: We present the rare reported case, to our knowledge, of epidural cement leakage after PKP at the segment of internal fixation and discuss the most likely etiologies and preventive measures for this condition.

Keywords: Cement leakage, Percutaneous kyphoplasty, Postoperative lumbar fusion, Surgical removal

\section{Background}

Thoracolumbar vertebral compression fractures result in intractable low back pain, progressive spinal deformity, and neurological damage. It is widely recognized that percutaneous kyphoplasty (PKP) is a minimally invasive procedure performed to stabilize the vertebral fracture and alleviate pain with shorter postoperative recovery time [1]. However, PKP has the potential risk of several surgical complications, the most common of which is bone cement leakage. Although most cases are asymptomatic, some severe cases of cement leakage into the

\footnotetext{
* Correspondence: yuky@pumch.cn

'Department of Orthopedics, Peking Union Medical College Hospital,

Chinese Academy of Medical Sciences, Shuaifuyuan No. 1, Wangfujing, Dongcheng District, Beijing 100730, China

Full list of author information is available at the end of the article
}

spinal canal, dura, or intervertebral foramen may cause neurological dysfunction or pulmonary embolism, and can be life-threatening [2-4]. To our knowledge, we present the rare reported case of an 81-year-old woman who suffered epidural cement leakage following PKP in the same vertebra with pedicle screws and clarify the most likely etiologies, clinical signs, and treatments of this rare condition.

\section{Case presentation}

A Chinese woman presented to Peking Union Medical College Hospital with complaints of low back pain and intermittent claudication. Based on physical examination and radiographic results, the diagnoses of lumbar spinal stenosis of L3-5 and lumbar spondylolisthesis of L4 were considered. She underwent posterior 
decompression, reduction of spondylolisthesis, internal fixation, and bone graft fusion from L3 -5 without any postoperative complications. The patient's initial recovery was uneventful, and her symptoms improved. Four years after the initial surgery, the patient was admitted to a local hospital for low back pain after a slip and fall. The possibility of acute vertebral compression fracture of L5 was considered (Fig. 1), and she underwent percutaneous kyphoplasty of L5 under local anesthesia.

The patient was hospitalized at our institution again due to the progression of low back pain with radiation to the left thigh 1 week after PKP surgery. The pain was severe and stabbing, and was aggravated by position changes. The numerical rating scale (NRS) scores for pain were 8 to 9 at the moment of severe pain. Physical examination revealed tenderness and percussion pain at the paravertebral and spinous processes of L5-S1 without restricted lumbar spine motion. Neurologic examination evaluated the muscle strength of left lower extremity as grade $4 / 5$ according to the British Medical Research Council (BMRC) scale. Hyporeflexia of the Achilles tendon was detected on the left side, but pathologic reflexes, superficial reflexes, and the upper limb neurologic examination were unremarkable. Bowel and bladder function remained normal and there were no difficulty evacuating or urinary incontinence. The plain $\mathrm{x}$-ray and CT scan revealed satisfactory position of the internal fixation but massive leakage of bone cement into the canal at the L5-S1 level, which resulted in significant compression of the S1 nerve root (Fig. 2).

Based on the patient's complaints, clinical signs, and radiological characteristics, a diagnosis of cement leakage following PKP was made. She then underwent posterior decompressive surgery. After resecting scar and granulation tissue from the initial surgery, the spinal cord was fully exposed and decompressed at L5-S1. While properly pulling the dural sac aside, epidural cement fragments, located in front of the spinal canal, were revealed and excised carefully without dural tear or any nerve root injury (Fig. 3).

The radiating pain and neurologic deficit were immediately relieved after surgery, but the muscle weakness of the left lower extremity remained unchanged. Postoperative CT images indicated complete removal of the epidural cement (Fig. 4). The patient's postoperative course was unremarkable and close follow-up was performed at 6 and 12 months postoperatively. No neurologic deterioration was observed in the postoperative period.

\section{Discussion and conclusions}

Instrumented spinal fusion represents the most common surgeries for various spinal disorders; however, there have been only three documented case reports of compression vertebral fracture occurring within vertebra existing instrumentation or within the solid vertebral fusion [5-7]. In our case, osteoporotic compression fracture of instrumented vertebra was considered based on image examination, history of initial lumbar fusion surgery and history of falls. Decrease of vertebral body bone mineral density after spinal fusion surgery was demonstrated because of biomechanical stresses, postoperative immobilization and mineral metabolism [8]. Currently, percutaneous kyphoplasty and percutaneous vertebroplasty (PVP) surgery have become the standard

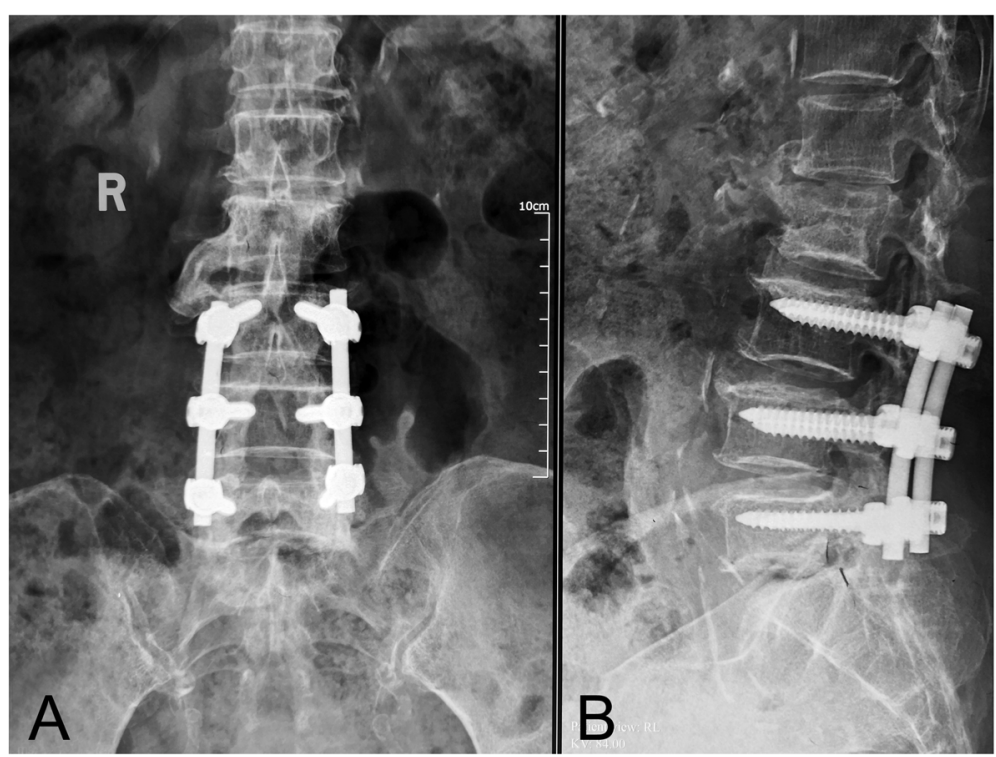

Fig. 1 Anterior-posterior (AP) and lateral X-ray images of the lumbar spine demonstrated a vertebral compression fracture of $L 5$ with good alignment of the construct from L3-5 


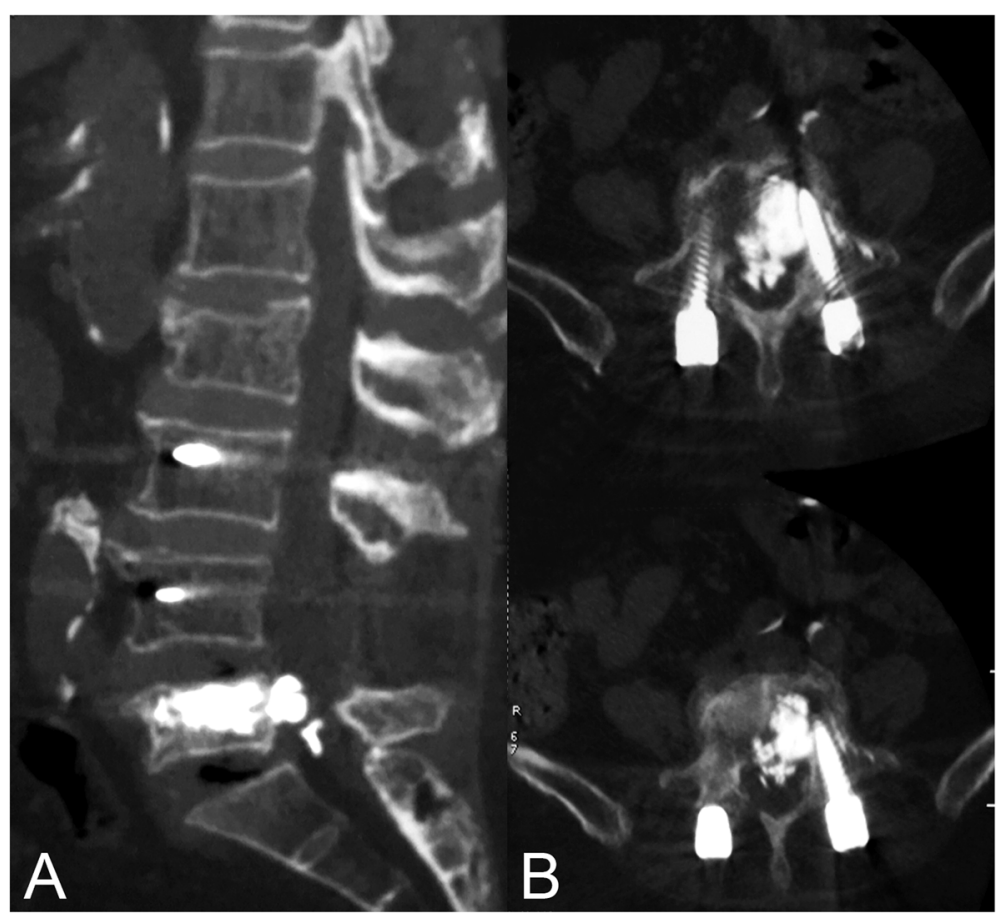

Fig. 2 A massive epidural cement leakage at L5-S1 was illustrated in the sagittal (a) and axial (b) reconstruction planes of the computed tomography scan

treatments for osteoporotic vertebral compression fractures, and are effective for rapid pain relief, restoration of vertebral body height, and enhancing strength and rigidity of the involved vertebrae by minimal invasive injection of bone cement $[9,10]$. However, as with any invasive procedure, complications related to percutaneous kyphoplasty are not uncommon, and include cement extravasation, pulmonary embolism, infection, epidural hematoma, systemic toxicity, and vertebral body fractures $[11,12]$. Although the incidence of bone cement leakage following PKP surgery is significantly lower than that of PVP due to application of balloon

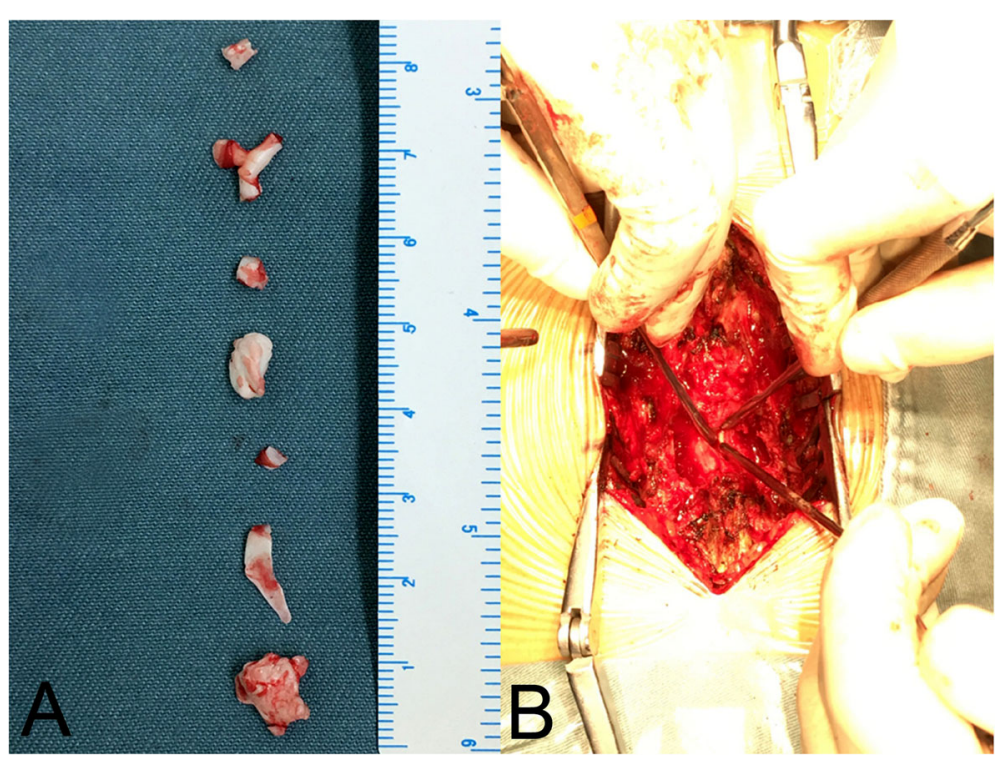

Fig. 3 Intraoperative images showed that several pieces of leaked cement fragments had been removed (a) and bone cement was exposed after pulling the dural sac aside (b) 


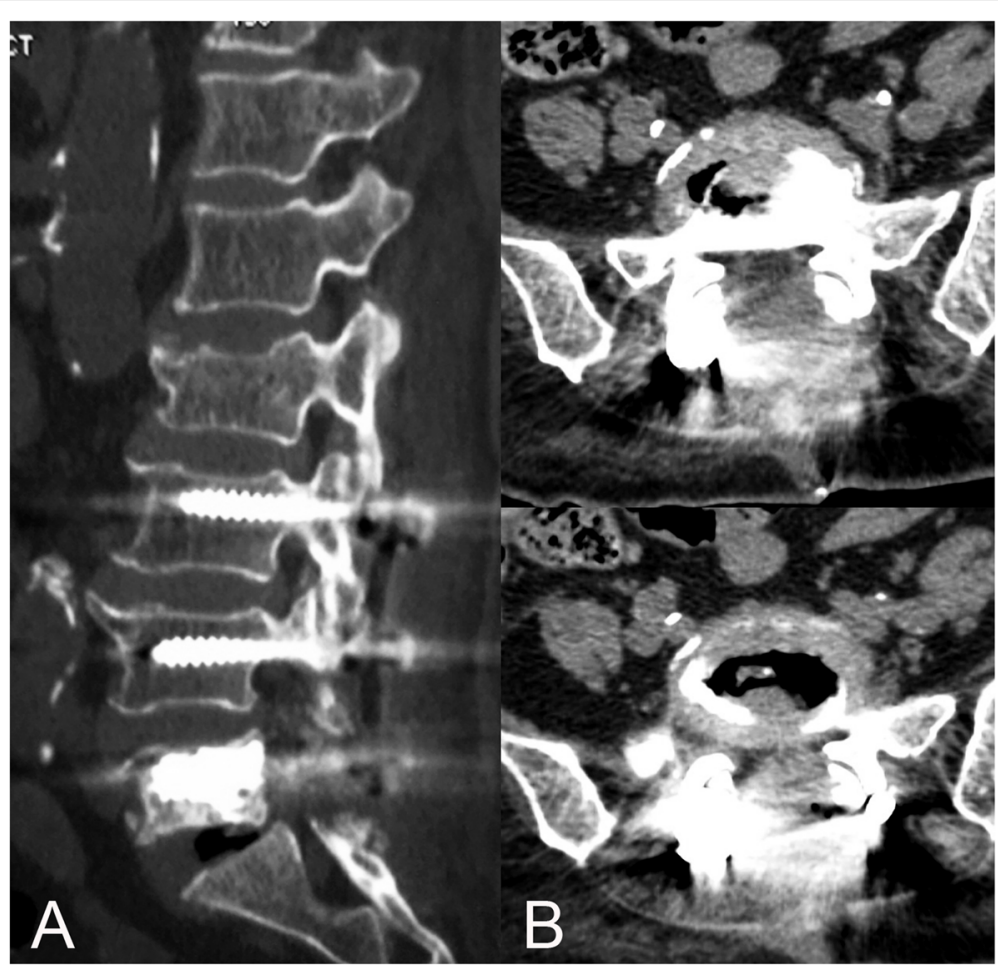

Fig. 4 Postoperative sagittal (a) and axial (b) CT images demonstrated good alignment of the implant and the complete removal of epidural leaked cement with thorough decompression of the spinal cord at L5-S1

dilation, cement leakage is still considered the most common complication of PKP [13].

At present, the incidence of bone cement leakage has varied between 5 and $87 \%$ in the literature $[14,15]$. The most probable reason for the significant difference in the rate of bone cement leakage is that many studies mainly rely on $\mathrm{x}$-ray examination for the diagnosis of bone cement leakage, rather than CT scan, which may result in missed diagnosis. Nieuwenhuijse et al. showed that the actual rate of bone cement leakage is higher than previously reported [14], and therefore, CT scans should be obtained to calculate the exact leakage rate and to assess persistent pain occurring postoperatively [16, 17]. Most clinical cement leakage following PKP requires no further treatment, so it is often overlooked clinically and is generally considered to be a normal phenomenon during surgery rather than a true complication. Nevertheless, when the bone cement leaks into the spinal canal or the intervertebral foramen, the spinal cord and the nerve root would be compressed to cause local or radicular pain, neurologic complications, and pulmonary embolization. Pain may be exacerbated when the cement leaks into the adjacent tissues or veins. Therefore, its potential harm is enormous and must be taken seriously in clinical practice.

Many factors contributing to the occurrence of bone cement leakage have been reported, including preoperative vertebral compression, viscosity of bone cement, the amount of injected bone cement, puncture approach, connection between the intravertebral cleft and basivertebral foramen, and preoperative verification of the fracture pattern (posterior wall or pedicle fracture) [18-21]. In our case, the compression fracture occurred in the L5 vertebral body with pedicle screws. Inserting the injector through pedicle with a screw or using an extrapedicular approach would be technically challenging. It was prone to penetrate into the spinal canal due to the obstruction of the pedicle screw when the PKP procedure was performed via the pedicle approach, thereby leading to cement leakage into the epidural space. The neural irritation symptoms due to epidural leakage could be related to the mass effect and secondary injury; to be more specific, the compression consequences of the spinal cord and nerve root were derived from cement extrusion into the spinal canal, and the exothermic reaction of the tissues during polymerization and cytotoxicity resulted from exposure of the tissues to residual bone cement. Considering our proposed risk factors, the following procedures may help prevent cement leakage following PKP: use of a bilateral transpedicular approach, a beveled needle, thicker consistency cement, and the avoidance of overfilling. It is critical to strictly follow the indications for surgery and complete preoperative imaging examinations, especially a CT scan, 
to identify the type of fracture. A PKP should be considered cautiously for patients with severe posterior wall vertebral injuries, the intravertebral cleft in vertebrae or compression fractures of the vertebrae with internal fixation. Intraoperative computed tomography-guided navigation and neuromonitoring might be useful tool in such complex cases.

These recommendations will help minimize the incidence of bone cement leakage after PKP. However, once cement leakage occurs, and is accompanied by a nerve deficit, the main goals of surgical intervention are to remove the bone cement, achieve spinal decompression, and relieve the secondary injury. As an alternative to conventional laminectomy, it has been reported that percutaneous endoscopic approach could achieve the targeted decompression with a smaller incision, decreased damage to soft tissues, and faster recovery. Moreover, the whole operation may be performed under local anesthesia, which allowed real-time neural function evaluation and had a lower risk of anesthesia-related complications [22]. Nevertheless, several limitations should be taken into consideration for minimal invasive surgery. Our patient underwent initial open surgery, which could be the challenge for percutaneous endoscopic interlaminar approach. On the other hand, transforaminal approach might be suffered from blockade of crista iliaca.

We report the rare case of intraspinal cement leakage after PKP at the level of the vertebrae with pedicle screws. It was prone to penetrate into the spinal canal due to the obstruction of the pedicle screw when the PKP procedure was performed, which reminded that PKP should be considered cautiously for compression fracture of vertebrae with internal fixation. Therefore, CT scans should be recommended to determine whether postoperative symptoms are related to cement extrusion. Immediate treatment for a neurologic deficit due to bone cement leakage is needed and the percutaneous endoscopic approach could be safely performed in patients with symptomatic cement leakage after a PKP procedure.

\section{Abbreviations}

PKP: Percutaneous kyphoplasty; NRS: Numerical rating scale; CT: Computed tomography; PVP: Percutaneous vertebroplasty

\section{Acknowledgments}

The author would like to thank the patients and their family members for their help and informed consent.

\section{Authors' contributions}

$Z Q L, K Y Y, J G$ and $Y P W$ joined the surgery, $X C$ and SYC were involved in information collection of the patient, $Z Q L$ and $K Y Y$ reviewed the literature and contributed to manuscript drafting, YPW and KYY were responsible for the revision of the manuscript. All authors issued final approval for the version to be submitted.

\section{Funding}

The acquisition of clinical data was supported by the National Natural Science Foundation of China (Grant No. 81572097).

\section{Availability of data and materials}

All the data supporting our findings are contained within the manuscript.

Ethics approval and consent to participate

Not applicable.

\section{Consent for publication}

Informed written consent was obtained from the patient for publication of this report and any accompanying images. A copy of the written consent is available for review by the Editor of this journal.

\section{Competing interests}

The authors declare that they have no competing interests.

\section{Author details}

'Department of Orthopedics, Peking Union Medical College Hospital, Chinese Academy of Medical Sciences, Shuaifuyuan No. 1, Wangfujing, Dongcheng District, Beijing 100730, China. ${ }^{2}$ Department of Neurosurgery, Peking Union Medical College Hospital, Chinese Academy of Medical Sciences, Shuaifuyuan No. 1, Wangfujing, Dongcheng District, Beijing 100730, China.

Received: 27 June 2019 Accepted: 5 April 2020

Published online: 15 April 2020

\section{References}

1. Filippiadis DK, Marcia S, Masala S, Deschamps F, Kelekis A. Percutaneous Vertebroplasty and Kyphoplasty: current status, new developments and old controversies. Cardiovasc Intervent Radiol. 2017:40(12):1815-23.

2. Grelat M, Le Van T, Fahed E, Beaurain J, Madkouri R. Rare complication of percutaneous technique: Intradural cement leakage and its surgical treatment. World Neurosurg. 2018;118:97.

3. Chen JK, Lee HM, Shih JT, Hung ST. Combined extraforaminal and intradiscal cement leakage following percutaneous vertebroplasty. Spine (Phila Pa 1976). 2007;32:E358-62.

4. Fadili Hassani S, Cormier E, Shotar E, Drir M, Spano JP, Morardet L, et al. Intracardiac cement embolism during percutaneous vertebroplasty: incidence, risk factors and clinical management. Eur Radiol. 2019;29:663-73.

5. Ha KY, Kwon SE, Kim KW, Oh IS, Lee YM. Vertebral compression fracture in the middle of fused segments without a history of injury: a case report. Spine (Phila Pa 1976). 2010;35(4):E137-9.

6. Hart RA, Hiratzka J, Deodhar A. Case report: vertebral compression fracture in a fused and instrumented lumbar segment. Clin Orthop Relat Res. 2007; 458:226-8.

7. Pirris SM, Kimes SM. Compression fracture in the middle of a chronic instrumented fusion that developed into pseudarthrosis after balloon kyphoplasty. J Neurosurg Spine. 2014;20(6):705-8.

8. Myers MA, Casciani T, Whitbeck MG Jr, Puzas JE. Vertebral body osteopenia associated with posterolateral spine fusion in humans. Spine (Phila Pa 1976). 1996;21(20):2368-71

9. Qi Y, Zeng Y, Jiang C, Liang B, Sui J, Zhao L, et al. Comparison of percutaneous Kyphoplasty versus modified percutaneous Kyphoplasty for treatment of osteoporotic vertebral compression fractures. World Neurosurg. 2019;122:e1020-7.

10. Lamy O, Uebelhart B, Aubry-Rozier B. Risks and benefits of percutaneous vertebroplasty or kyphoplasty in the management of osteoporotic vertebral fractures. Osteoporos Int. 2014;25:807-19.

11. Kita K, Takata Y, Higashino K, Yamashita K, Tezuka F, Sakai T, et al. Surgical Removal of Circumferentially Leaked Polymethyl Methacrylate in the Epidural Space of the Thoracic Spine after Percutaneous Vertebroplasty. Surg J (N Y). 2017;10:e1-5.

12. Kulkarni $A G$, Shah SP, Deopujari CE. Epidural and intradural cement leakage following percutaneous vertebroplasty: a case report. J Orthop Surg (Hong Kong). 2013;21:365-8.

13. Lee JH, Lee JH, Jin Y. Surgical techniques and clinical evidence of vertebroplasty and kyphoplasty for osteoporotic vertebral fractures. Osteoporos Sarcopenia. 2017;3:82-9. 
14. Nieuwenhuijse MJ, Van Erkel AR, Dijkstra PD. Cement leakage in percutaneous vertebroplasty for osteoporotic vertebral compression fractures: identification of risk factors. Spine J. 2011;11:839-48.

15. Zapałowicz K, Radek M. Percutaneous balloon kyphoplasty in the treatment of painful vertebral compression fractures: effect on local kyphosis and oneyear outcomes in pain and disability. Neurol Neurochir Pol. 2015;49:11-5.

16. Yeom JS, Kim WJ, Choy WS, Lee CK, Chang BS, Kang JW. Leakage of cement in percutaneous transpedicular vertebroplasty for painful osteoporotic compression fractures. J Bone Joint Surg Br. 2003;85:83-9.

17. Schmidt R, Cakir B, Mattes T, Wegener M, Puhl W, Richter M. Cement leakage during vertebroplasty: an underestimated problem? Eur Spine J. 2005;14:466-73.

18. Ding J, Zhang Q, Zhu J, Tao W, Wu Q, Chen L, et al. Risk factors for predicting cement leakage following percutaneous vertebroplasty for osteoporotic vertebral compression fractures. Eur Spine J. 2016;25:3411-7.

19. Yilmaz A, Çakir M, Yücetaş CŞ, Urfali B, Üçler N, Altaş M, et al. Percutaneous Kyphoplasty: Is Bilateral Approach Necessary? Spine (Phila Pa 1976). 2018;43: 977-83.

20. Wang C, Fan S, Liu J, Suyou L, Shan Z, Zhao F. Basivertebral foramen could be connected with intravertebral cleft: a potential risk factor of cement leakage in percutaneous kyphoplasty. Spine J. 2014;14:1551-8.

21. Li S, Wang C, Shan Z, Liu J, Yu T, Zhang X, et al. Trabecular Microstructure and Damage Affect Cement Leakage From the Basivertebral Foramen During Vertebral Augmentation. Spine (Phila Pa 1976). 2017;42:E939-48.

22. Şenturk S, Akyoldas G, Ünsal ÜÜ, Yaman O, Özer AF. Minimally invasive Translaminar endoscopic approach to percutaneous Vertebroplasty cement leakage: technical note. World Neurosurg. 2018;117:15-9.

\section{Publisher's Note}

Springer Nature remains neutral with regard to jurisdictional claims in published maps and institutional affiliations.

Ready to submit your research? Choose BMC and benefit from:

- fast, convenient online submission

- thorough peer review by experienced researchers in your field

- rapid publication on acceptance

- support for research data, including large and complex data types

- gold Open Access which fosters wider collaboration and increased citations

- maximum visibility for your research: over $100 \mathrm{M}$ website views per year

At BMC, research is always in progress.

Learn more biomedcentral.com/submissions 